Questioning dual antimicrobial therapy as first line in recent Australian Therapeutic Guidelines

Corresponding author:

Dr Leanne Teoh

Melbourne Dental School

University of Melbourne

Carlton, Victoria 3053

Australia

Email: leanne.teoh@unimelb.edu.au

Dr Wendy Thompson

University of Manchester

Manchester, England

United Kingdom

Professor Michael McCullough

Melbourne Dental School

University of Melbourne

Carlton, Victoria 3053

Australia

This is the author manuscript accepted for publication and has undergone full peer review but has not been through the copyediting, typesetting, pagination and proofreading process, which may lead to differences between this version and the Version of Record. Please cite this article as doi: $10.1111 /$ ADJ.12783

This article is protected by copyright. All rights reserved 
DR. LEANNE TEOH (Orcid ID : 0000-0002-9138-813X)

Article type : Original Article

Questioning dual antimicrobial therapy as first line in recent Australian Therapeutic Guidelines

Corresponding author:

Dr Leanne Teoh

Melbourne Dental School

University of Melbourne

Carlton, Victoria 3053

Australia

Email: leanne.teoh@unimelb.edu.au

Dr Wendy Thompson

University of Manchester

Manchester, England

United Kingdom

Professor Michael McCullough

Melbourne Dental School

University of Melbourne

This article is protected by copyright. All rights reserved 
Carlton, Victoria 3053

Australia

\section{Questioning dual antimicrobial therapy as first line in recent Australian Therapeutic} Guidelines

International efforts to tackle the development and spread of infections resistant to antibiotics have led to a drive towards the use of narrow-spectrum antibiotics wherever possible. Until a recent change in Therapeutic Guidelines: Oral and Dental Version 3 (TG3), ${ }^{1}$ Australia was ahead of the international dental community in this respect, with phenoxymethylpenicillin monotherapy recommended for most acute spreading odontogenic infections. ${ }^{2} \mathrm{We}$ welcome the comprehensive nature of the new guidelines. However, we question the changed antibiotic regimen to dual therapy and the various combinations of antibiotics recommended.

Antibiotic resistance is a global public health problem. Antibiotic use is a key driver of antibiotic resistance - the more we use antibiotics, the more likely it is that resistance will develop. ${ }^{3}$ Broad-spectrum antibiotics select for a wider range of bacteria compared to narrow-spectrum agents. ${ }^{3}$ Antibiotic-resistant odontogenic infections are associated with longer hospital stays and poorer clinical outcomes. ${ }^{4}$ The key principle for clinicians is responsible prescribing, involving prescribing only when necessary, choosing an antibiotic with the narrowest, but appropriate spectrum to minimise the selection of antibiotic-resistant bacteria. Previous editions of Therapeutic Guidelines Oral and Dental ${ }^{2}$ recommended that dentists use firstly, the narrow-spectrum phenoxymethylpenicillin for a spreading odontogenic infection, and then to only add metronidazole 48 hours later if clinically indicated with non-resolution. In direct contrast to the direction of the international dental community, the latest recommendations in $\mathrm{TG} 3{ }^{1}$ have introduced metronidazole to be always prescribed in combination with phenoxymethylpenicillin; metronidazole with amoxicillin; or amoxicillin with clavulanic acid as first-line therapy for a spreading odontogenic infection without severe or systemic features.

Antibiotic prescribing guidelines differ worldwide. Nevertheless, first line prescribing recommendations in dental guidelines from the Faculty of General Dental Practice (United Kingdom (UK)), ${ }^{5}$ the Scottish Dental Clinical Effectiveness Program, ${ }^{6}$ and the United States (US) guidelines ${ }^{7}$ all recommend penicillin monotherapy, either amoxicillin or phenoxymethylpenicillin. The oral and dental health of the UK and US is similar to that in Australia with regard to the number of decayed, missing, and filled teeth, those edentulous 
and access to oral health services. ${ }^{8-11}$ Thus, it would be reasonable to assume that Australian dentists do not have clinically exceptional circumstances that require dual antimicrobial therapy as first-line treatment while at the same time susceptibility data demonstrate that this is unnecessary.

It is difficult to understand the shift in recommendation in $\mathrm{TG} 3{ }^{1}$ to dual therapy as first-line treatment with an increased spectrum for spreading odontogenic infections without severe or systemic features. There is no evidence that there is a change in the spectrum to a more anaerobic infection if there is spread beyond the confines of the tooth and into the surrounding tissues. In fact there is evidence to show that the spectrum of bacteria in dentoalveolar and endodontic infections are the same. ${ }^{12}$ Regardless of where the bacteria spread to (the periapical area, or a secondary space eg. buccal, canine space), they originated from the same source (the root canal system). There is a prevalence of anaerobic, Gram negative bacteria in deep space infections in those patients who require hospitalisation for severe odontogenic infections, ${ }^{4}$ however this is clearly not localised odontogenic infections with non-severe extra-oral swelling for which these recommendations address.

There is some evidence in the literature of increasing rates of resistance to penicillins in anaerobic bacteria, particularly Prevotella spp. However, there are no studies that report antibiotic susceptibility in representative target populations, an Australian dental patient in outpatient clinics. Various studies of anaerobic bacteria from patients in Russia, ${ }^{13}$ Romania ${ }^{14}$ and Europe ${ }^{15}$ report high rates of Prevotella spp. resistant to penicillin. However, the studied population and location of isolated bacteria are incomparable to a typical dental Australian patient presenting with a spreading odontogenic infection.

The fundamental principle of managing an odontogenic infection is to drain any suppuration and remove the source of the infection, either via extraction, endodontic treatment, or periodontal treatment. Active dental treatment is always required. Lesions progress beyond the confines of the tooth when the bacteria saturate the capacity of the body's defence mechanisms. ${ }^{16}$ There is always the potential that the spread of infection potentially can compromise airways, result in sepsis and significant morbidity. ${ }^{17,}{ }^{18}$ Nevertheless, there is no evidence to show that the use of penicillin monotherapy in a non-severe extra-oral swelling with concurrent appropriate dental treatment is insufficient treatment that leads to hospitalisation. 
A recent South Australian study undertook a retrospective assessment of severe deep space infections in hospitalised patients demonstrating an increased prevalence of anaerobic strains. ${ }^{4}$ Even though this cohort of patients is not comparable to the outpatient setting, penicillin resistance was observed in only $10.8 \%$ of isolates. $^{4}$

Antibiotic resistance patterns vary by country, ${ }^{19}$ as the development of resistance and transmission of antibiotic-resistant genes depends on a range of factors including local antibiotic use (in humans, animals and agriculture), availability of antibiotics, and hygiene and infection control in healthcare facilities. ${ }^{20}$ Susceptibility studies on bacteria commonly isolated from odontogenic infections in different countries across Europe, the USA, Brazil and Thailand between 2002 and $2014^{21-24}$ have shown marked differences in patterns of susceptibility/resistance to antibiotics, such that nearly $50 \%$ of isolates in Spain were found to be resistant to metronidazole. ${ }^{23}$ Guidelines for antibiotic use in dentistry should therefore be based on local resistance data where possible.

Antibiotics prescribed for dental conditions have a wider impact than just targeting the infection. Antibiotics taken orally are associated with dysbiosis, with a reduction in the number and diversity of microorganisms within the body's microbiome. ${ }^{25}$ Metronidazole in particular increases the risk of intestinal enterococcal colonisation and expansion, and betalactam administration does not. ${ }^{26}$ Antibiotic-related colitis, results from the selection of Clostridioides difficile in the gut. This condition can be life threatening and its link to dentists working in community settings has been established in the USA. ${ }^{27}$ Dental antibiotics may be a risk to patient safety as well as to the population more generally through the development and spread of bacteria resistant to antibiotics, alterations in the gut microbiome, and adverse events such as antibiotic associated diarrhoea.

Based on principles of antibiotic stewardship to optimise antibiotic use and minimise adverse effects, the authors recommend that monotherapy (either phenoxymethylpenicillin or amoxicillin) be used initially as an adjunct to an operative dental procedure for acute spreading odontogenic infections, with the addition of metronidazole only if clinical improvement is not observed. There is a clear need for more local and relevant antibiotic susceptibility data to influence guideline recommendations. Where no applicable local data exist, the relevance and applicability of international studies should be employed with caution. Using broad-spectrum antibiotics through dual therapy as first-line guidance is not in 
line with international dental guidelines. Moreover, clinical guideline recommendations should be based on Australian susceptibility data where possible.

\section{References}

1. Oral and Dental Expert Group. Therapeutic Guidelines: Oral and Dental Version 3. Melbourne, Australia: Therapeutic Guidelines Ltd; 2019.

2. Oral and Dental Expert Group. Therapeutic guidelines: oral and dental. Version 2 ed. Melbourne: Therapeutic Guidelines Limited; 2012.

3. Australian Commission on Safety and Quality in Health Care (ACSQHC). AURA 2016: first Australian report on antimicrobial use and resistance in human health. Sydney: ACSQHC; 2016. 4. Liau I, Han J, Bayetto K, May B, Goss A, Sambrook P, et al. Antibiotic resistance in severe odontogenic infections of the South Australian population: a 9-year retrospective audit. Aust Dent J. 2018;63(2):187-192.

5. FGDP (UK). Antimicrobial Prescribing for GDPs. URL: "https://www.fgdp.org.uk/guidancestandards/antimicrobial-prescribing-gdps". Accessed 1 February 2020.

6. Guidance Dental Group. Drug Prescribing for Dentistry: Scottish Dental Clinical Effectiveness Programe; 2016, January.

7. Lockhart PB, Tampi MP, Abt E, Aminoshariae A, Durkin MJ, Fouad AF, et al. Evidence-based clinical practice guideline on antibiotic use for the urgent management of pulpal- and periapicalrelated dental pain and intraoral swelling: A report from the American Dental Association. Journal of the American Dental Association (1939). 2019;150(11):906-921.

8. NHS Digital. NHS Dental Statistics for England - 2017-18, Annual Report [PAS] [Available from: https://digital.nhs.uk/data-and-information/publications/statistical/nhs-dentalstatistics/2017-18-annual-report.

9. Blinkhorn AS. Comparison of the dental health of adults and children living in NSW with their counterparts in the US and UK. N S W Public Health Bull. 2009;20(3-4):52-55.

10. Slade GD, Nuttall N, Sanders AE, Steele JG, Allen PF, Lahti S. Impacts of oral disorders in the United Kingdom and Australia. Br Dent J. 2005;198(8):489-493.

11. Manton DJ FM, Gikas A, Ivanoski S, McCullough MJ, Peres MA, Roberts-Thomson K, Skinner J, Irving E, Seselja A, Calder R, Harris B, Lindberg R, Millar L, Nichols T. Australia's Oral Health Tracker: Technical Paper. Melbourne: Australian Health Policy Collaboration, Victoria University; 2018.

This article is protected by copyright. All rights reserved 
12. Brook I, Lewis MA, Sandor GK, Jeffcoat M, Samaranayake LP, Vera Rojas J. Clindamycin in dentistry: more than just effective prophylaxis for endocarditis? Oral Surg Oral Med Oral Pathol Oral Radiol Endod. 2005;100(5):550-558.

13. Shilnikova, II, Dmitrieva NV. Evaluation of antibiotic susceptibility of Bacteroides, Prevotella and Fusobacterium species isolated from patients of the N. N. Blokhin Cancer Research Center, Moscow, Russia. Anaerobe. 2015;31:15-18.

14. Bancescu G, Didilescu A, Bancescu A, Bari M. Antibiotic susceptibility of 33 Prevotella strains isolated from Romanian patients with abscesses in head and neck spaces. Anaerobe. 2015;35(Pt A):41-44.

15. Veloo ACM, Tokman HB, Jean-Pierre H, Dumont $Y$, Jeverica S, Lienhard R, et al. Antimicrobial susceptibility profiles of anaerobic bacteria, isolated from human clinical specimens, within different European and surrounding countries. A joint ESGAI study. Anaerobe. 2020;61:102111.

16. Marton IJ, Kiss C. Protective and destructive immune reactions in apical periodontitis. Oral Microbiol Immunol. 2000;15(3):139-150.

17. Sundararajan K, Gopaldas JA, Somehsa H, Edwards S, Shaw D, Sambrook P. Morbidity and mortality in patients admitted with submandibular space infections to the intensive care unit. Anaesth Intensive Care. 2015;43(3):420-422.

18. Han J, Liau I, Bayetto K, May B, Goss A, Sambrook P, et al. The financial burden of acute odontogenic infections: the South Australian experience. Aust Dent J. 2020;65(1):39-45.

19. Centre for Disease Dynamics EaP. Resistance Map URL: "https://resistancemap.cddep.org/". Accessed 1 February 2020.

20. Forum WE. Global Risks 2013, Eighth Edition, Insight Report.

21. Lang PM, Jacinto RC, Dal Pizzol TS, Ferreira MB, Montagner F. Resistance profiles to antimicrobial agents in bacteria isolated from acute endodontic infections: systematic review and meta-analysis. Int J Antimicrob Agents. 2016;48(5):467-474.

22. Baumgartner JC, Xia T. Antibiotic susceptibility of bacteria associated with endodontic abscesses. J Endod. 2003;29(1):44-47.

23. Bresco-Salinas M, Costa-Riu N, Berini-Aytes L, Gay-Escoda C. Antibiotic susceptibility of the bacteria causing odontogenic infections. Med Oral Patol Oral Cir Bucal. 2006;11(1):E70-75.

24. Dingsdag SA, Hunter N. Metronidazole: an update on metabolism, structure-cytotoxicity and resistance mechanisms. J Antimicrob Chemother. 2018;73(2):265-279.

25. Ferrer M, Mendez-Garcia C, Rojo D, Barbas C, Moya A. Antibiotic use and microbiome function. Biochem Pharmacol. 2017;134:114-126.

This article is protected by copyright. All rights reserved 
26. Pilmis B, Le Monnier A, Zahar JR. Gut Microbiota, Antibiotic Therapy and Antimicrobial Resistance: A Narrative Review. Microorganisms. 2020;8(2).

27. Bye M WT, Holzbauer S. . Antibiotic prescribing for dental procedures in communityassociated Clostridium difficile cases, Minnesota, 2009-2015. Open Forum Infect Dis 2017(4(suppl 1):S1. ). 


\section{University Library}

\section{- M M N E R VA A gateway to Melbourne's research publications}

Minerva Access is the Institutional Repository of The University of Melbourne

Author/s:

Teoh, L;Thompson, W;McCullough, M

Title:

Questioning dual antimicrobial therapy as first line in recent Australian Therapeutic Guidelines

Date:

2020-06-25

Citation:

Teoh, L., Thompson, W. \& McCullough, M. (2020). Questioning dual antimicrobial therapy as first line in recent Australian Therapeutic Guidelines. AUSTRALIAN DENTAL JOURNAL, 65 (4), pp.302-304. https://doi.org/10.1111/adj.12783.

Persistent Link:

http://hdl.handle.net/11343/275949 